technology education of specialists and of the public, inside and outside with technology, and technology with production; and scientific research and technological development: these are all areas in which many specific, realistic, and effective proposals await implementation. Such programmes must involve the direct participation of working scientists and technologists the world over.

The most important aim is to ensure that UNCSTD, unlike the long list of other UN conferences, produces something tangible and operationally useful, even if only on a modest scale.

Dr Moravcsik is at the Institute of Theoretical Science, University of Oregon

\section{A ten-year ban on large and poorly prepared meetings}

\section{Ward Morehouse}

Now that the final UNCSTD Preparatory Committee meeting is over, it is possible to predict with a modest measure of certainty the likely outcome of the conference - a programme of action filled with platitudinous recommendations for national governments, especially in developing countries, to do more for and with science and technology for development; a new high-level committee and some rearrangement of concerned secretariats at the UN; a charge to the UN Development Programme and the specialised agencies to pay more attention to science and technology in their activities; and possibly some very marginal increse in the resources available from development agencies, mostly by reallocating existing budgets.

In the meantime, the cost of UNCSTD is approaching $\$ 50$ million - not just the direct UN secretariat and conference costs ( $\$ 7.8$ million) but also the lodging, food and international travel expenses of the 4,000 people expected in Vienna during the last two weeks of August (\$6 million), the professional compensation of the 2,500 government delegates and UN officials preparing for and attending the conference ( $\$ 3.8$ million), the host country's budgetary allocation for UNCSTD ( $\$ 5$ million), the five PrepCom meetings (\$3.2 million), the preparation of national papers and related preparatory activities of 100 governments and an assortment of UN and other international agencies ( $\$ 14.6$ million) and the 100 or more international conferences and seminars spawned by UNCSTD ( $\$ 8$ million).

The likely outcome of UNCSTD seems marginal in relation to such expenditures. Even if a four-part package involving a $\$ 200$ million science and technology fund, which is now being quietly negotiated, were to happen (an outside chance), it is not clear whether the result would do more to benefit scientists in North and South who say they are concerned with development or to improve the lives of poor people by bringing them the benefits of science and technology - through, as the principal UNCSTD discussion paper expresses one of the major goals of the conference, "the establishing of a just and equitable social order."

In fact, the real danger of exercises like UNCSTD is that they divert attention from the underlying economic, social, and political causes of human suffering and deprivation by deluding us into thinking these problems can be solved by science and technology alone.

Hence I propose, as one important action to enhance the realisation of the UNCSTD goal expressed above, a ten-year moratorium on large and indifferently prepared international meetings on science and technology for development, and similar global problem-solving conferences, while we search for more costeffective ways to link the North-South dialogue to meaningful efforts to ameliorate the human condition. The money thus saved can be used in the coming decade to get on with the task of improving poor peoples' lives by whatever means are most appropriate, including - but not limited to - science and technology.

Dr Morehouse is President of the Council on International and Public Affairs, New York

\section{Radical changes in UN procedures and policies}

\section{A.B. Zahlan}

THE deliberations that underlie UNCSTD revolve around three particular problem areas. North-South relations, internal transformations of developing countries and the UN system as an instrument of technical assistance. Although all three require attention, it is perhaps fitting that UNCSTD should be primarily concerned with how the performance of the UN system could be improved. The UN system is not merely a source of aid; it also diffuses procedures and models that are often copied by the institutions of the Third World. The subject matter concerned with each of these problem areas is extremely complex; the extent of awareness of the specifics of the processes is poor; and the vested interests in the bureaucracies of UN agencies, ministries of Third World countries, the business communities and the governments of industrial countries are such that a stalemate has been attained. This situation is not in the interest of either the world community or the UN system; and it is certainly not in the interest of the Third World.

The efforts so far deployed to effect the

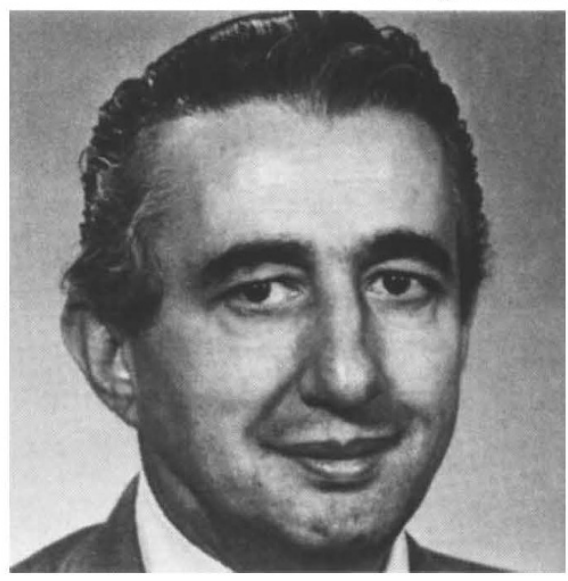

Da Costa: UNCSTD Secretary-General changes called for by the New International Economic Order and by UNCSTD are too limited to dislodge established practices. The tens of thousands of persons employed in this multi-billion dollar 'aid industry' cannot spontaneously switch off past practices and become pioneers of the New International Economic Order and UNCSTD. The 'aid industry' operates on the basis of concepts of development that originate in both advanced and developing countries, and all these parties must share in altering accepted dogma. The management of the UN system has often attracted attention, but so far the system has not been opened up to provide factual data on its operations, performance and the policy implications of its practices. Yet the technological development of the Third World, along the lines proposed by UNCSTD, calls for radical changes in the procedures and policies underlying the operations of UN agencies. In theory the UN system is subject to scrutiny by member states at the level of the General Assembly, and during the general conferences of the respective agencies. In fact, however, very little of the necessary factual examination and analysis actually takes place at any of these gatherings. Short-term interests dominate, and few of the delegates possess the adequate information to assess the facts. Currently these international discussions are remote from the scientists, institutions and problems of the Third World. It is only through a dedicated concern about the field aspects of science and technology that the debate can be enriched with facts and realism.

The challenge facing the Third World in the UN system today is not to win a vote or to issue a new proclamation, but rather to initiate a process powerful enough to transform the practices of the system. A revitalised UN system has a good chance of accelerating the mobilisation of the internal resources of developing countries. These resources are formidable and all too often underestimated.

Prof Zahlan has been a scientific advisor to the UN (on ACAST) and Professor of Physics at the American University, Beirut. He is presently a visiting fellow at the Science Policy Research Unit, University of Sussex 